\title{
Exposure of Ceramics and Ceramic Matrix Composites in Simulated and Actual Combustor Environments
}

\author{
Karren L. More, Peter F. Tortorelli, \\ Mattison K. Ferber, Larry R. Walker, and James R. Keiser \\ Oak Ridge National Laboratory \\ Oak Ridge, Tennessee
}

\author{
Narendernath Miriyala, William D. Brentnall, and Jeffrey R. Price \\ Solar Turbines Incorporated \\ San Diego, California
}

\begin{abstract}
A high-temperature, high-pressure, tube furnace has been used to evaluate the long term stability of different monolithic ceramic and ceramic matrix composite materials in a simulated combustor environment. All of the tests have been run at 150 psia, $1204^{\circ} \mathrm{C}$, and $15 \%$ steam in incremental $500 \mathrm{~h}$ runs. The major advantage of this system is the high sample throughput; $>20$ samples can be exposed in each tube at the same time under similar exposure conditions. Microstructural evaluations of the samples were conducted after each $500 \mathrm{~h}$ exposure to characterize the extent of surface damage, to calculate surface recession rates, and to determine degradation mechanisms for the different materials. The validity of this exposure rig for simulating real combustor environments was established by comparing materials exposed in the test rig and combustor liner materials exposed for similar times in an actual gas turbine combustor under commercial operating conditions.
\end{abstract}

\section{INTRODUCTION}

Continuous fiber-reinforced ceramic matrix composites (CFCCs) are being developed to replace several metal components in industrial stationary gas turbines. One such application that has received a significant amount of attention in the past few years is the uncooled CFCC combustor liner. The use of CFCC materials for this component can result in significantly decreased $\mathrm{CO}$ and $\mathrm{NO}_{\mathrm{x}}$ emissions even at increased combustor wall temperatures; i.e. $-1200^{\circ} \mathrm{C}$ or higher (van Roode et al., 1993).

In May, 1997, Solar Turbines began field tests of its Centaur $50 S$ natural gas engine fitted with first stage monolithic ceramic blades and CFCC combustor liners at Atlantic Richfield Company (ARCO) Western Energy, Bakersfield, CA (Price et al., 1998 and Stambler, 1997). This test was a major milestone for Solar's Ceramic Stationary Gas Turbine (CSGT) Program under the sponsorship of the U.S. Department of Energy (DOE). It was also one of the first application-specific tests under DOE's CFCC Program.

Full acceptance of ceramic materials for this particular application, however, is still a daunting task. There is a lack of long-term exposure/testing data for many of the commerciallyavailable and proprietary CFCC materials, especially in corrosive environments similar to those encountered in an actual turbine combustor. It is desirable to use a laboratory test to screen the viability of the different CFCC compositions; using actual CFCC combustor liners (even sub-scale) in real engine tests to generate data is an exceptionally expensive undertaking. Prior knowledge of a CFCC's stability is extremely important before placing that material in a field test. Burner rig studies have been conducted on different SiC materials (Robinson and Smialek, 1998, Etori et al., 1997), however, these tests are somewhat limited in that only a few samples can be exposed simultaneously and typical runs are only $100 \mathrm{~h}$. Long term data is then extrapolated from the $100 \mathrm{~h}$ 
results. No burner rig data are currently published for $\mathrm{SiC}$ based composites. Since the operating lifetime goal for the CFCC combustor liners will ultimately be $>30,000 \mathrm{~h}$, a complete understanding of the microstructural stability for the many CFCC materials after long exposures in these environments is critical for their future placement in this application and other hot-section components.

The major goals of this program were twofold: (1) to provide a means for exposing large numbers of different CFCC materials to a simulated combustor environment for long periods of time (initially up to at least $3000 \mathrm{~h}$ ) and (2) to determine the primary degradation/recession mechanisms for individual CFCC compositions as a function of time at the maximum temperature the CFCC liners experience during engine tests. This is being accomplished using a hightemperature, high-pressure, tube furnace which was originally constructed to conduct corrosion/leak tests on ceramic materials for a steam reformer application (Keiser et al., 1996). This furnace permits simultaneous exposure of many specimens at temperatures up to $1550^{\circ} \mathrm{C}$ and pressures as high as 500 psia. As described below, the Oak Ridge National Laboratory (ORNL) rig has been used to successfully duplicate the materials degradation/recession observed for a $1000 \mathrm{~h}$ field test of a CFCC combustor liner run in a Solar Turbines Centaur $50 \mathrm{~S}$ engine at ARCO Western Energy (referred to as the ARCO test). Microstructural analyses of the CFCC liners removed from the ARCO test as well as samples from the first exposure tests (verification runs) in the ORNL rig will be described here.

\section{EXPERIMENTAL PROCEDURE}

The ORNL rig consisted primarily of a fumace and gas supply system (Keiser et al., 1996). The furnace, capable of operating at temperatures up to $1550^{\circ} \mathrm{C}$, accommodated six vertically loaded, $8.9 \mathrm{~cm}$ diameter tubes, two of which were dedicated to this study. The $1.2 \mathrm{~m}$ long tubes, used to hold the samples and contain the pressurized test atmosphere, were composed of $\mathrm{SiC}$ (Hexoloy SA ${ }^{\mathrm{TM}}$ ). The tubes were supported by a metal flange which also provided a gas-tight seal. A combination of flexure and tensile CFCC specimens were loaded into a $3.2 \mathrm{~cm}$ diameter alumina carrier tube which was then inserted into the $\mathrm{SiC}$ tube and suspended at the top by the flange. A "slow flow" gas supply system provided a pressurized mixture of steam and premixed gas to each tube. A schematic of a SiC tube assembly is shown in Figure 1 and a typical specimen loading configuration for the alumina carrier is shown in Figure 2. Each alumina tube can hold as many as 30 combined tensile and flexure specimens. In order to best simulate the combustor environment, all tests were conducted in air at $1204^{\circ} \mathrm{C}\left(2200^{\circ} \mathrm{F}\right), 15 \%$ water vapor (balance air), and 150 psia. Each test was run for $500 \mathrm{~h}$, after which the specimens were carefully removed, weighed and measured, and selectively cut for microstructural analysis. Depending on the amount of degradation observed, the specimens were either placed back in the furnace for additional $500 \mathrm{~h}$ exposures under the same conditions or removed from the test. In this way, the most promising materials could be exposed for very long times and new materials could replace less stable materials removed from the tests.

The CFCC liners from the ARCO field test were used as the microstructural "standard" for the first several runs in the ORNL rig. The ability of the ORNL rig to simulate a combustion environment and reproduce the microstructural damage observed in the ARCO liners was one of the most important goals of this study. The dimensions of the inner and outer liners used in the ARCO test were nominally $33 \mathrm{~cm}$ and $76 \mathrm{~cm}$ in diameter, respectively, with a height of $20 \mathrm{~cm}$ and a thickness of $2.5 \mathrm{~mm}$. The outer surface of the inner liner and the inner surface of the outer liner were the working surfaces of the two liners. Both the inner and outer liners were made of AlliedSignal Composites Inc. (ACI) Enhanced SiC/SiC CFCC which had Ceramic Grade (CG) Nicalon ${ }^{\mathrm{TM}}$ fibers, a pyrocarbon interfacial coating, a $\mathrm{SiC}$ matrix produced by isothermal chemical vapor infiltration (CVI), and a thin ( $-60 \mu \mathrm{m}$ thick) $\mathrm{SiC}$ seal coat (Gray et al., 1996). This material was selected to be used in the first field test because of its performance in several $100 \mathrm{~h}$ sub-scale combustor tests at Solar Turbines (Simpson et al., 1997). During the ARCO test, the liners were periodically inspected for surface dmage about every two weeks using a borescope. The extent of damage, usually in the form of visible changes in surface color or structure, dictated the point at which the liners were removed from the engine test. $I_{n}$ the case of the ARCO test, the engine test was actually stopped after -948 h as a result of foreign object damage (FOD) and subsequent failure of the monolithic ceramic blades. Visual inspection of the liners showed considerable surface damage and the decision was made to remove them from the test for examination. Both liners were still completely intact.

The engine tested liners were first sent to Argonne National Laboratory (ANL) for non-destructive evaluation (NDE). After NDE, both liners were sent to ACI where tensile specimens (all residual strength measurements were performed at $\mathrm{ACI}$ ) and sections for microstructural analysis were cut. ORNL received a total of three $2.54 \mathrm{~cm}$ wide sections; two full (top to bottom) sections from the outer liner and one full section from the inner liner, as illustrated in Figure 3. Several samples were cut from each section at ORNL with each sample representing different amounts of visually observed surface damage. Metallographic cross-sections were prepared from each to examine damage as a function of depth from the exposed surface. The samples were structurally and compositionally analyzed using an electron microprobe equipped with energy and wavelength dispersive spectrometers. Selected samples were also prepared for transmission electron microscopy to determine the extent of thermal damage to the fibers. 


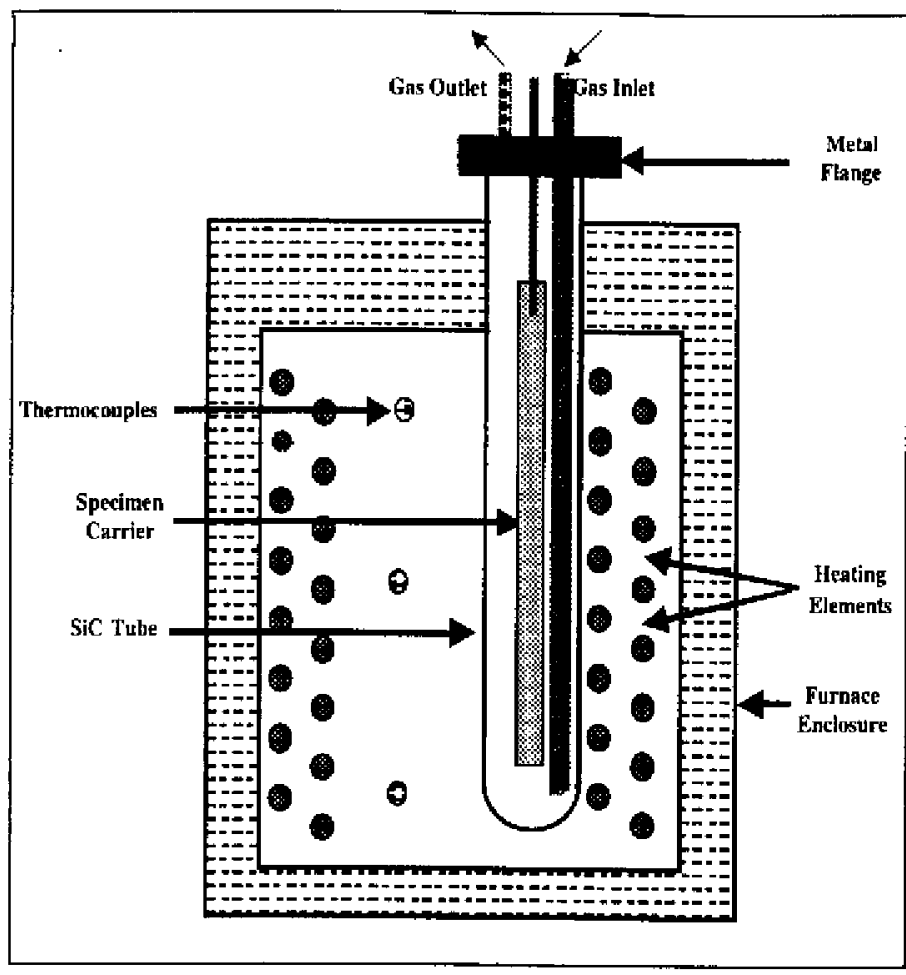

Figure 1. Schematic of SiC tube and gas assembly in ORNL rig. Furnace holds six vertically-loaded tubes.

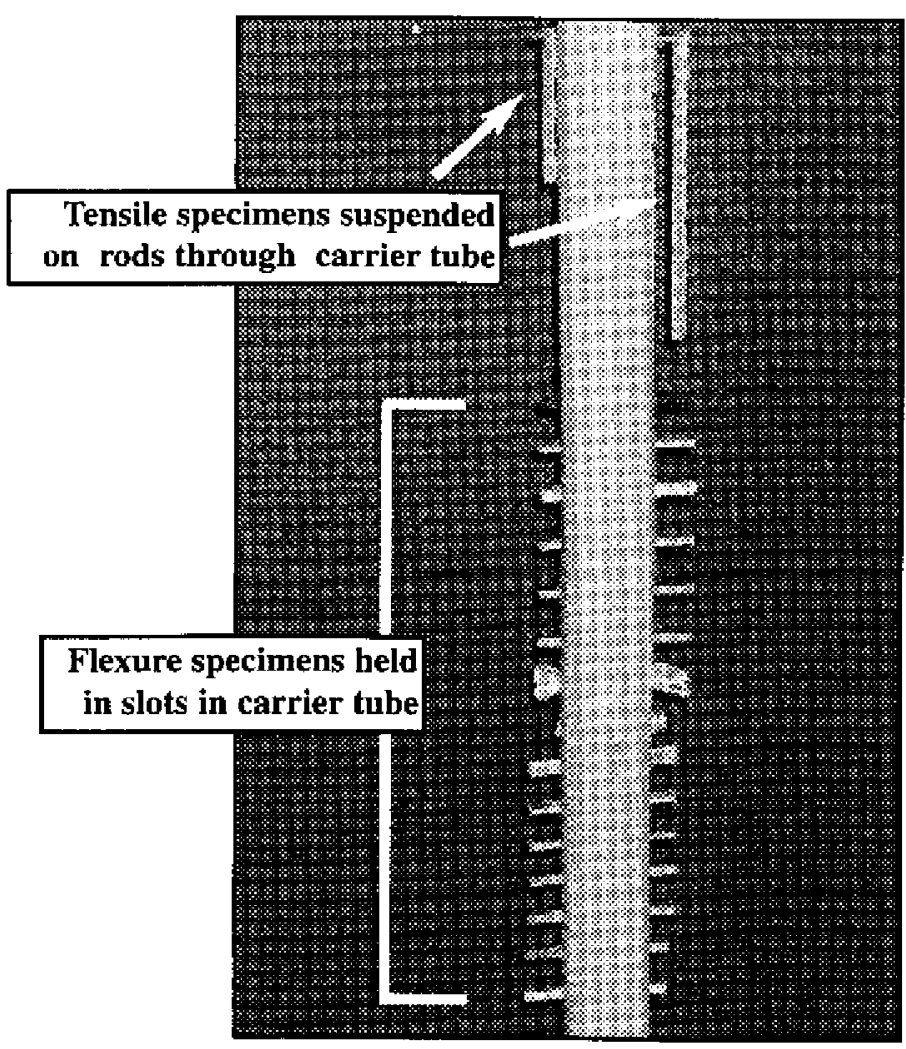

Figure 2. Alumina carrier tube that holds tensile and flexure specimens for exposure in ORNL rig.

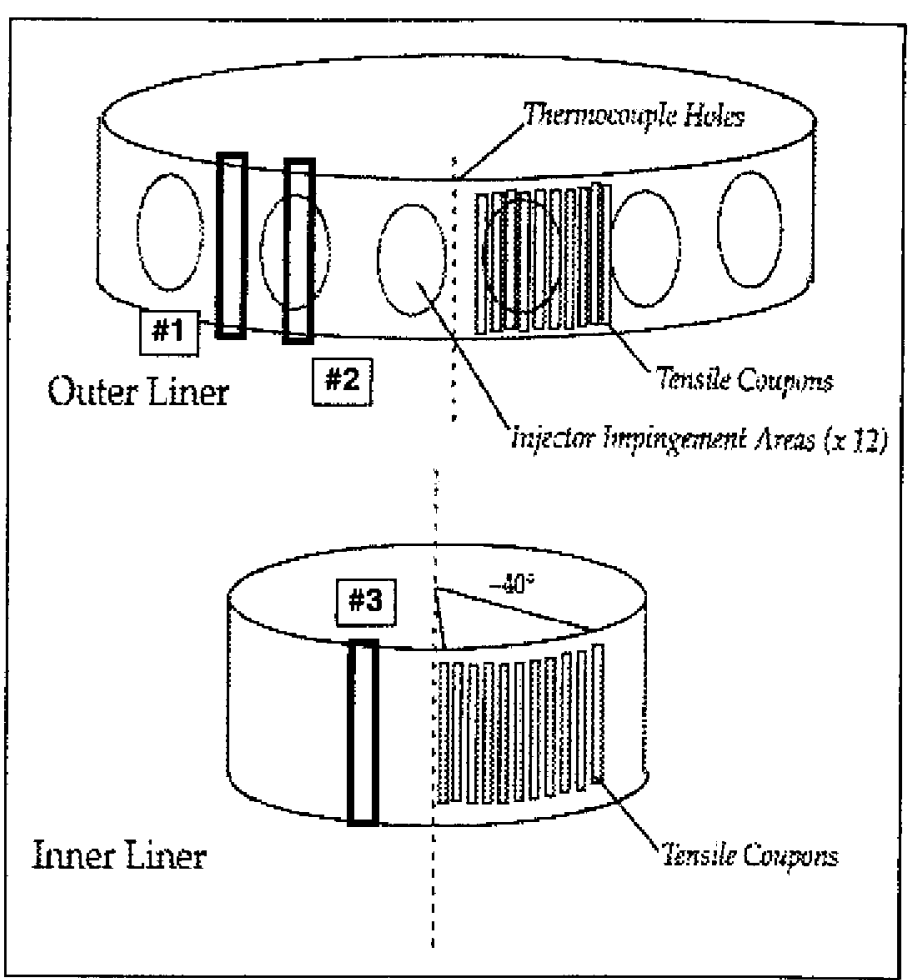

Figure 3. Schematic of specimens cut from inner and outer CFCC combustor liners after ARCO test.

The primary purpose of the first few ORNL rig exposures was to verify the ability of these tests to simulate the combustor environment. Enhanced $\mathrm{SiC} / \mathrm{SiC}$ tensile bars, which were co-processed with the ARCO liners (and thus assumed to have the same starting microstructure) were exposed in two successive $500 \mathrm{~h}$ runs to match the total time that the ARCO liners were engine tested. SiC Hexoloy $\mathrm{SA}^{\mathrm{TM}}$ flexure bars and several different $\mathrm{Si}_{3} \mathrm{~N}_{4}$ bars were also included as standards in order to assess the oxidation kinetics of known materials. The oxidation behavior of these monolithic ceramics in the presence of water vapor, albeit at lower pressures, has been well documented in the literature (see for example Opila and Hann, 1997, Fox et al., 1997).

After each $500 \mathrm{~h}$ exposure, the specimens were removed from the ORNL rig, weighed, and sectioned. Microstructural examinations were systematically conducted to measure oxide product thickness and surface recession. It was determined from these initial runs that the weight and dimensional measurements were not reliable as a result of unavoidable handling during removal from the furnace. Such handling could result in loss of oxide product. Thus, microstructural measurements were used to determine the oxidation kinetics. 


\section{RESULTS AND DISCUSSION}

\section{Microstructural Analysis of ARCO Liners}

Visual inspection of the ARCO liners after $1000 \mathrm{hrs}$ showed "white" areas on the working surfaces of both the inner and cuter liners. These white areas were initially observed on the exposed liner surfaces after $\sim 500 \mathrm{~h}$ during a visual burescope inspection. The localized white spots on the outer liners corresponded directly with the 12 injector impingement areas on the inner surface of this liner. The white spots indicated a range of localized temperatures since the surfaces between and around these white spots appeared rclatively unchanged. The exposed surface of the inner liner, in particular, exhibited severe damage over most of its surface. Figure 4 shows the inner surface of the outer liner; note the localized white damaged regions that corresponded directly with the injector impingement areas.

Microstructural examination of the inner liner showed that signiticant surface recession occurred during the ARCO test. As shown in Figures 5 (a) and 5(b), comparing sections of the inner liner from the top surface (CFCC exposed to the lowest temperature during the engine test) and from the center of the exposed surface of the inner liner (near maximum damage urea), respectively, recession of about $20 \%$ of the inner liner thickness was observed and another $25 \%$ of the CFCC exhibited microstructural damage (see arrows in Figure $5(\mathrm{~b})$ ). The damage assessment indicated that not only was the protective $\mathrm{SiC}$ seal coat (initially $-60 \mu \mathrm{m}$ thick) completely removed during engine testing, but the CFCC constituents themselves had reacted to form a low melting point glass at the liner surface. The oxidation of the $\mathrm{SiC}$ seal coat (and matrix) resulted in the rapid formation of surface silica; the silica then formed volatile reaction products in the water containing environment (Opila and Jacobsen, 1998, Robinson and Smialek, 1998) resulting in accelerated $\mathrm{SiC}$ recession. The projected $\mathrm{CVD} \mathrm{SiC}$ recession after 1000 h under lean-burn conditions, estimated from burner rig studies performed at NASA Lewis, is $-150 \mu \mathrm{m}$ at $1200^{\circ} \mathrm{C}, 0.6 \mathrm{~atm} \mathrm{H}_{2} \mathrm{O}$, and a gas velocity of $33 \mathrm{~m} / \mathrm{s}$ (Robinson and Smialek, 1998). The maximum temperature during the ARCO test could not be accurately measured since the thermocouples failed in the early stages of the field test. However, based on the intermittent visual inspections of the liners during the ARCO test, the seal coat on the inner liner (and locally on the outer liner) was breached relatively early in the test indicating that the temperature was $\sim 1200^{\circ} \mathrm{C}$, and possibly as high as $1260^{\circ} \mathrm{C}$ at the hot spors on the inner liner.

Typical microstructural damage observed at the outer surface of the inner liner is shown in Figure 6. Large "pools" of glass were observed; the CG Nicalon ${ }^{\mathrm{TM}}$ fibers and associated matrix constituents reacted with the glass and entire fiber tows were consumed during glass formation (as shown in Figure 7). While most of the glass was primarily silica, small amounts of boron were found in these areas (additional matrix constituents were the source of the B), which caused a reduction in the glass melting point. Mitrix constituents containing boron therefore contributed significantly to the gluss formation. Similarly damaged areas were also identified well below the exposed surface of the inner liner (arrows in Figure 6) and were primarily associated with areas of large porosity (these composites typically were only about $85-90 \%$ dense), indicating significant oxidation in these areas also. Formation and subsequent recession of the glass product was the primary degradation mechanism of the outer surface of the inner liner. The process was accelerated by the damage formed below the surface.

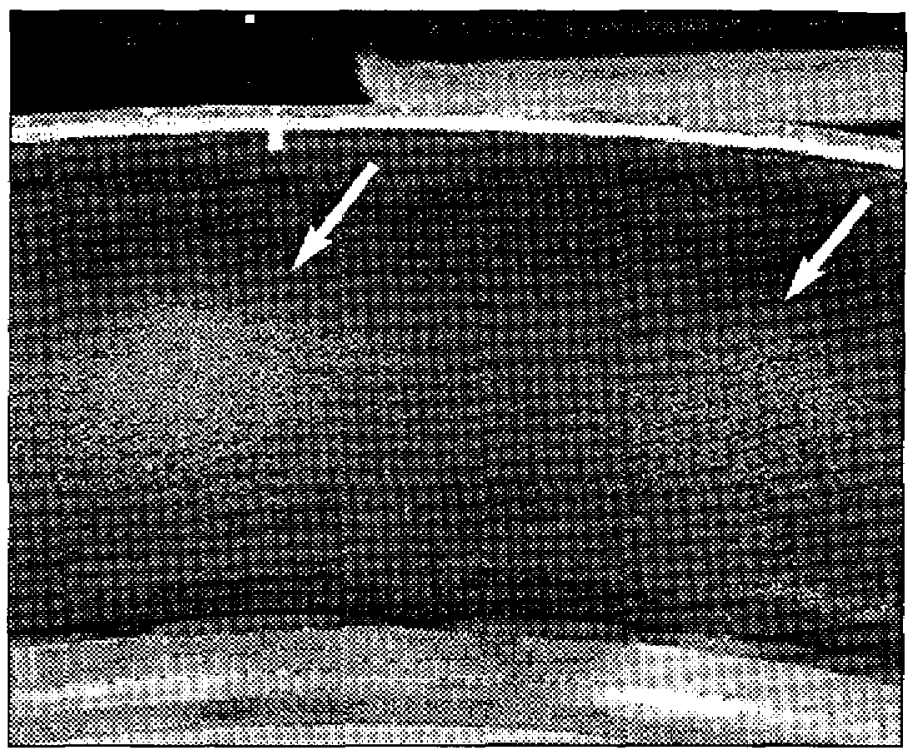

Figure 4. Portion of the inner surface of outer liner; note two of the localized white damaged regions that corresponded directly with injector impingement areas (arrows).

Evaluation of the injector impingement areas on the inner surface of the outer liners showed similar microstructural damage as that observed on the inner liner, albeit to a much lesser extent; the $\mathrm{SiC}$ seal coat was completely removed in these localized areas, but only the top CG Nicalon ${ }^{\mathrm{TM}}$ fiber ply was adversely affected, as shown in Figure 8 . In the areas surrounding the injector impingement regions, the $\mathrm{SiC}$ seal coat was somewhat thinned (the thickness of the remaining seal coat depended primarily on the local temperature), but remained intact. The surfaces of pores below the liner surface were oxidized (this was most pronounced below the injector impingement areas) and in many instances, matrix and fiber damage around these pores was observed well into the bulk of the underlying $C F C C$. Clearly, on both the inner and outer liner working surfaces, the "white areas" indicated complete loss of the protective $\mathrm{SiC}$ seal coat. This will be used in future borescope inspections as an indication of the point at which the protective seal coat is breached. 


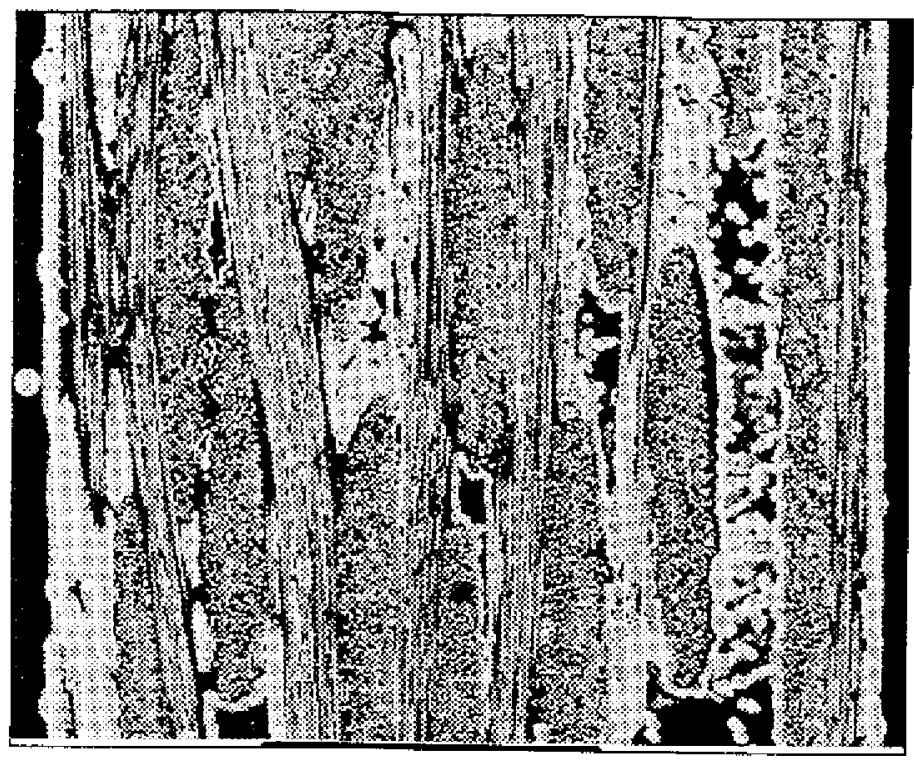

(a) Unexposed inner liner

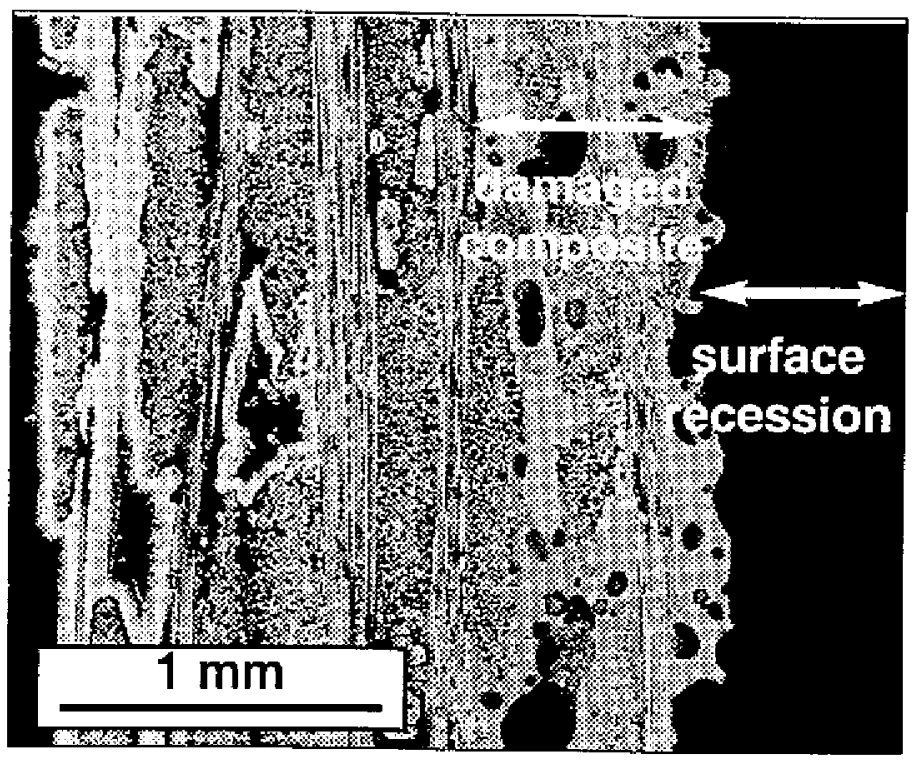

(b) Inner liner after ARCO field test

Figure 5. Microstructural damage at outer surface of inner liner after the ARCO test. (a) Section of liner taken from top (cooler) edge of liner showing intact $\mathrm{SiC}$ seal coat and nondamaged composite and (b) section taken from center of exposed surface showing significant surface recession, loss of most of the seal coat, and extensive composite damage below the surface. Damage regions below surface consist primarily of reacted matrix constituents that form glass and loss of fibers.

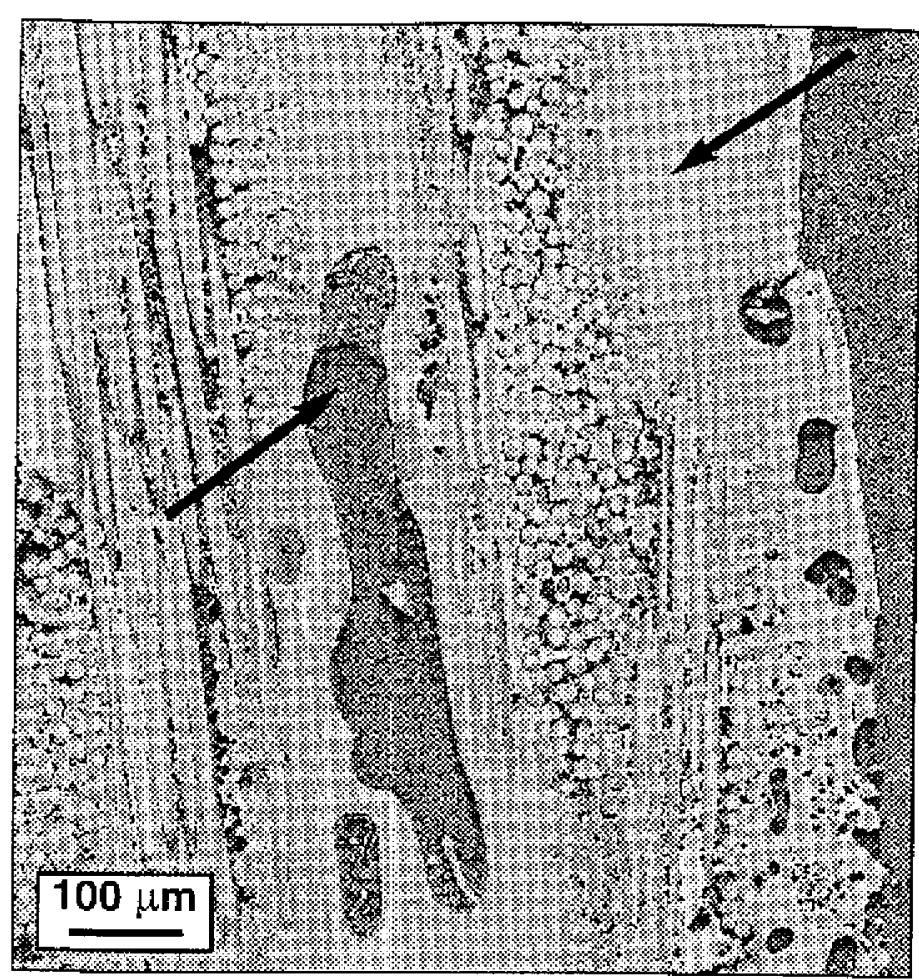

Figure 6. Typical microstructural damage observed at the outer surface of the inner liner. Arrows indicate areas of "pooled" glass observed throughout damaged region.

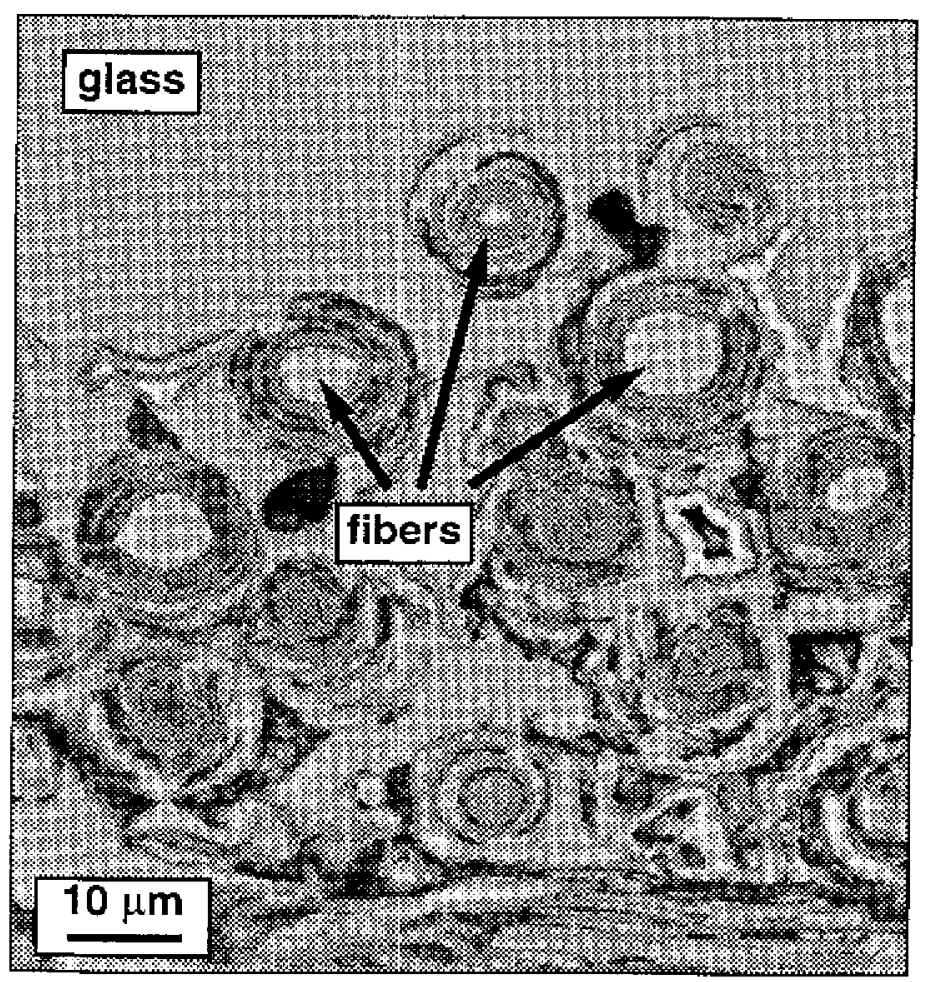

Figute 7. CG Nicalon Tim fibers were consumed during extensive matrix glass formation within damaged revions near exposed surface of inner liner. Arrows indicate fibers at different stages of reaction with glass. 


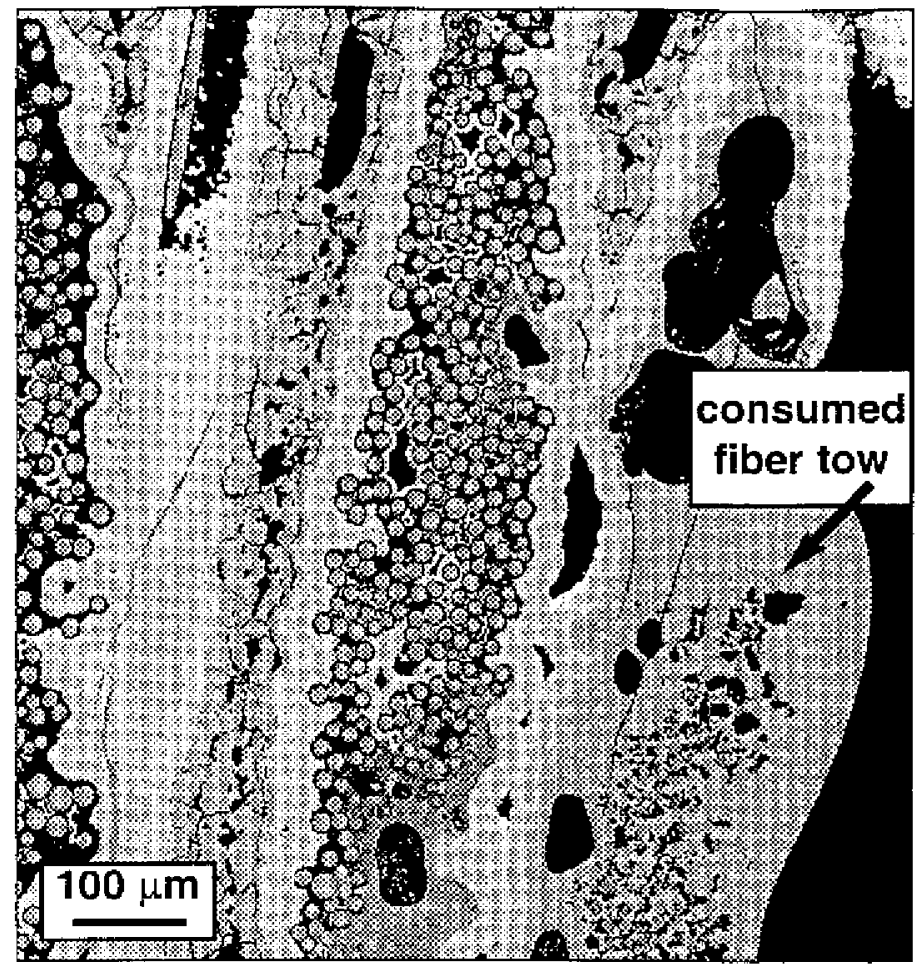

Figure 8. Typical microstructural damage observed at the inner surface of the outer liner after the ARCO test. Microstructural degradation was similar to that observed for the inner liner.

Verification of ORNL Steam Rig for Simulating Combustor Environment Corrosion

Two types of Enhanced $\mathrm{SiC} / \mathrm{SiC}$ samples were included in the initial run of the ORNL rig: tensile bars of material co-processed with the ARCO liners which had a SiC seal coat thickness of $-60 \mu \mathrm{m}$ and a similar composite with a much thicker $-300 \mu \mathrm{m} \mathrm{SiC} \mathrm{seal} \mathrm{coat.} \mathrm{The} \mathrm{second} \mathrm{material}$ provided additional data for the rig assessment; kinetic data for CVD SiC could be accumulated in addition to data for SiC (Hexoloy $\mathrm{SA}^{\mathrm{TM}}$ ) for comparison with existing burner rig data (Robinson and Smialek, 1998, Opila and Hann, 1997). The primary goal of the first two ORNL runs. however, was to verify that the ORNL rig could reproduce the microstructural degradation observed in the liners after the ARCO test.

Visual inspection of the Enhanced $\mathrm{SiC} / \mathrm{SiC}$ tensile specimen after the first $500 \mathrm{~h}$ run showed that all the surfaces were covered with a white oxide product and glass bubbles. An important observation made after the first $500 \mathrm{~h}$ exposure was that extensive degradation occurred at cut or open surfaces of the specimens. These areas had to be carefully avoided during microstructural evaluation since these could lead to excessive amounts of material degradation that would not be representative of the extent of damage found in combustor liners (which have no open or cut ends). Figure 9 is a photograph of the Enhanced $\mathrm{SiC} / \mathrm{SiC}$ specimen removed after $500 \mathrm{~h}$. Note the excessive amount of glass protruding from the surface cut before the test; not only is there usuilly no seal coat on these ends, but the exposed fiber ends and open areas into the matrix contribute to accelerated degradation. The specimen for microstructural analysis was cut at least $1 \mathrm{~cm}$ below this open surface.

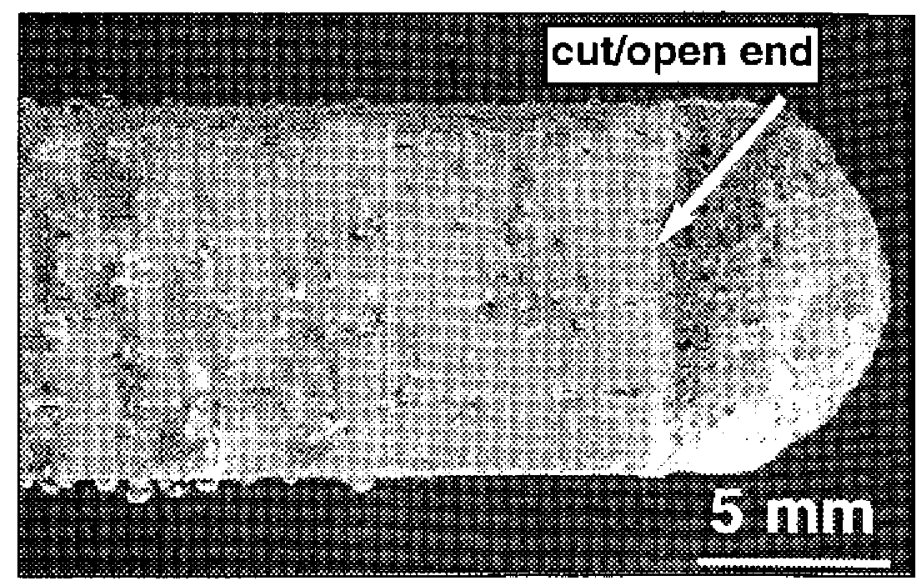

Figure 9. Surface of Enhanced $\mathrm{SiC} / \mathrm{SiC}$ specimen after $500 \mathrm{~h}$ exposure in ORNL rig. Material was co-processed with CFCC liners in ARCO test. Specimen geometry contributed to significant glass formation at cut/open edges.

Cross-sections of the as-processed Enhanced $\mathrm{SiC} / \mathrm{SiC}$ composite before and after exposure in the ORNL rig for $500 \mathrm{~h}$ are shown in Figures 10(a) and 10(b), respectively. The SiC seal coat was fully oxidized across the specimen surface and fiber tows below the surface showed areas of constituent reaction (arrows in Figure 10(b)). The damaged composite areas in the ORNL-exposed specimen were structurally similar to those observed for the same material after the ARCO test (see Figure 6); localized areas of constituent reaction (glass formation) are noted in Figure 10(b). The same specimen was placed back in the ORNL rig for an additional $500 \mathrm{~h}$, thus exposing the material for approximately the same amount of time achieved in the ARCO test. After $1000 \mathrm{~h}$ in the ORNL rig, the microstructural degradation was extensive, as shown in Figure 11, and was nearly identical to that observed for the same material engine tested at ARCO. There was significant glass formation at the surface.

The Enhanced $\mathrm{SiC} / \mathrm{SiC}$ sample with a thick CVD SiC seal coat was used to determine the CVD $\mathrm{SiC}$ oxidation/recession rate in the ORNL rig. Figure 12 shows the oxidation of the SiC seal coat for three sequential $500 \mathrm{~h}$ exposures. It was determined from direct microstructural measurements that the $\mathrm{SiC}$ seal coat recessed by oxidation at a maximum linear rate of approximately $45 \mu \mathrm{m} / 500 \mathrm{~h}$. Clearly, the oxidation/recession rate of the $\mathrm{SiC}$ was accelerated in the ORNL rig compared to rates reported previously for CVD SiC exposed at lower water vapor pressures (Opila, 1994 and Opila, 


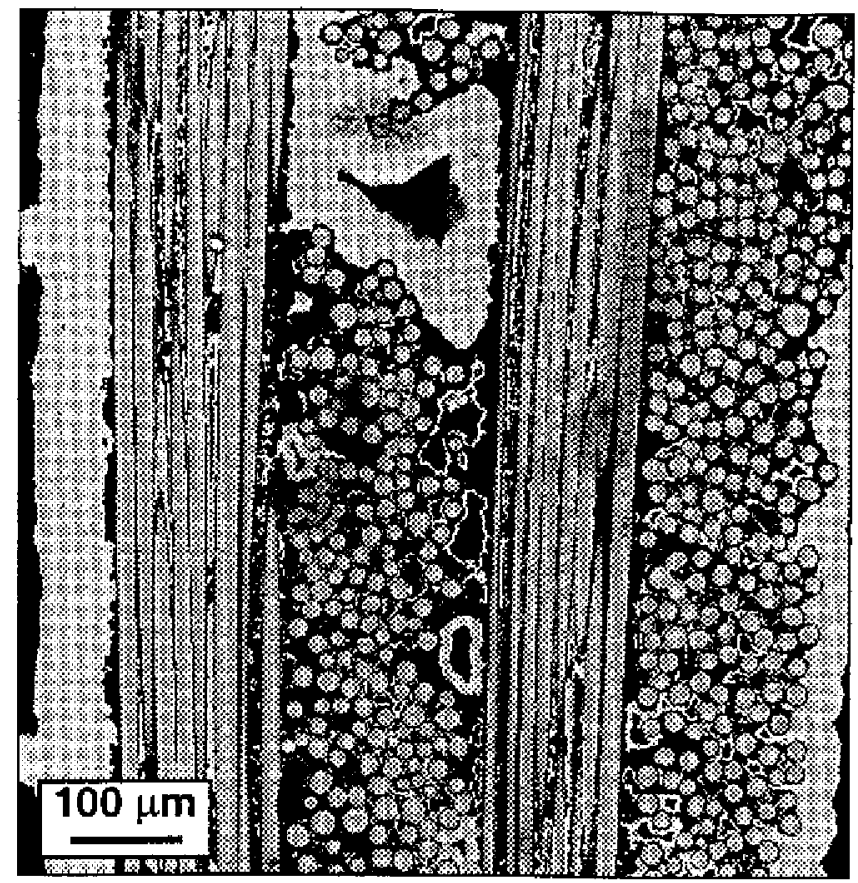

(a) As-processed

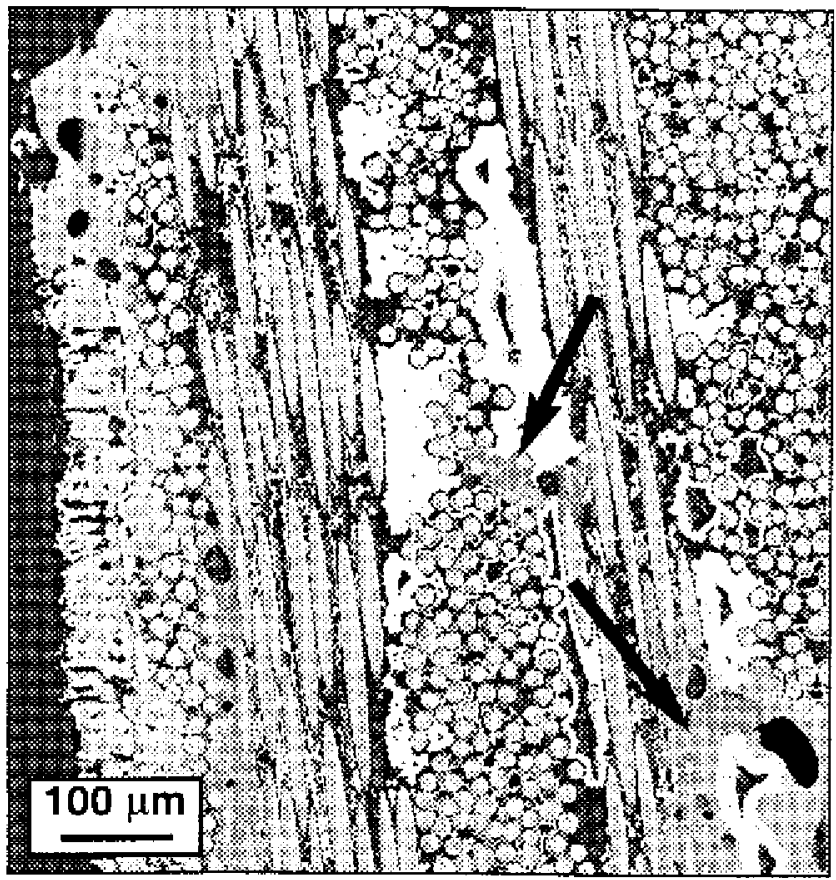

(b) Exposed $500 \mathrm{~h}$ in ORNL rig

Figure 10. A comparison of cross-sections of the (a) asprocessed Enhanced $\mathrm{SiC} / \mathrm{SiC}$ material and (b) the Enhanced $\mathrm{SIC/SiC}$ CFCC after exposure in the ORNL rig for $500 \mathrm{~h}$ Compare localized microstructural degradation (reacted matrix constituents) in Figure 10(b) (indicated by arrow) to inner liner degradation shown in Figure 6.
1999). A complete kinetic analysis of this phenomenon is currently ongoing. It is interesting to note that most of the silica formed on the specimen surfaces during exposure in the ORNL rig was not removed by volatilization as it would be at higher gas flow velocities (Robinson and Smialek, 1998). However, the bulk of this silica is not protective against ongoing oxidation and the rate of $\mathrm{SiC}$ recession is sufficiently high to compromise the seal coat and allow for extensive composite damage in approximately the same amount of exposure time as found in the ARCO test. This is evident in the depth of the damage observed in the Enhanced $\mathrm{SiC} / \mathrm{SiC}$ composite after exposure in the ORNL rig; the amount of material lost is not indicative of total damage because the envitonment penetrates into the composite and causes the same type of microstructural degradation below the surface.

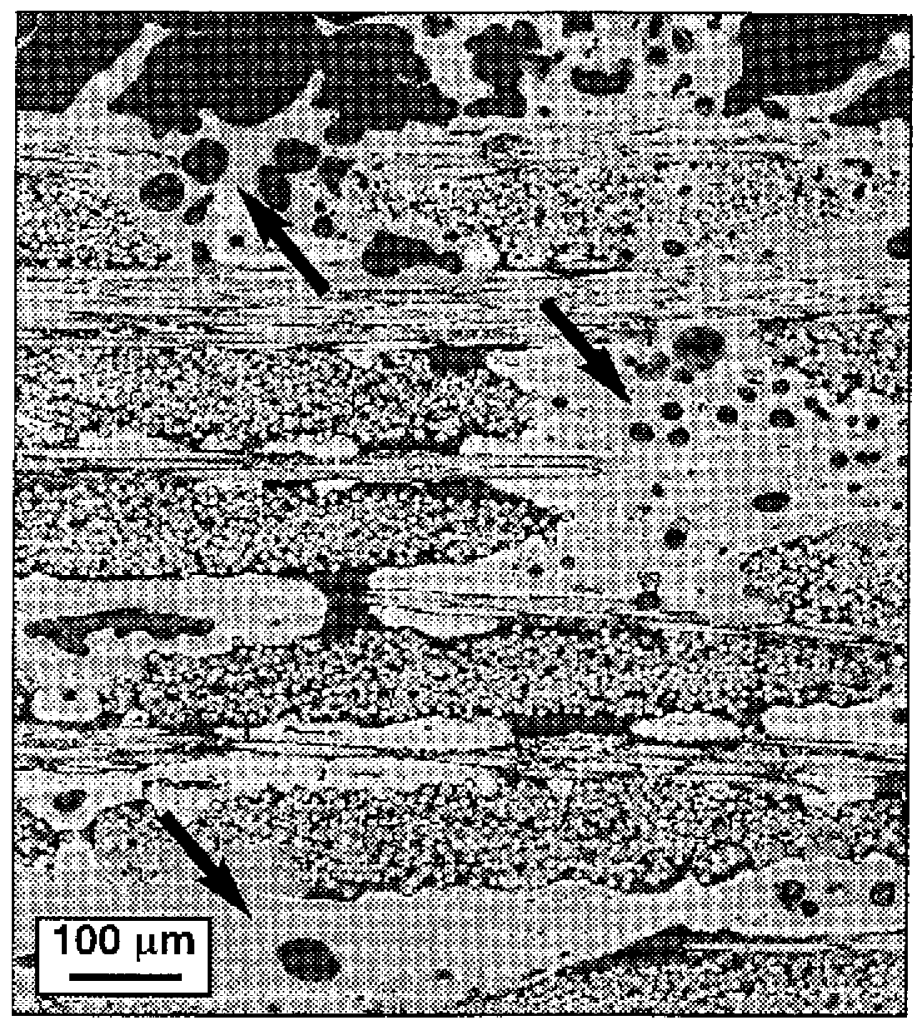

Figure 11. Microstructural degradation of Enhanced $\mathrm{SiC} / \mathrm{SiC}$ CFCC after exposure in the ORNL rig for $1000 \mathrm{~h}$. Compare microstructural degradation (reacted matrix constituents) in Figure 11 (indicated by arrow) to inner liner degradation in Figure 6. 

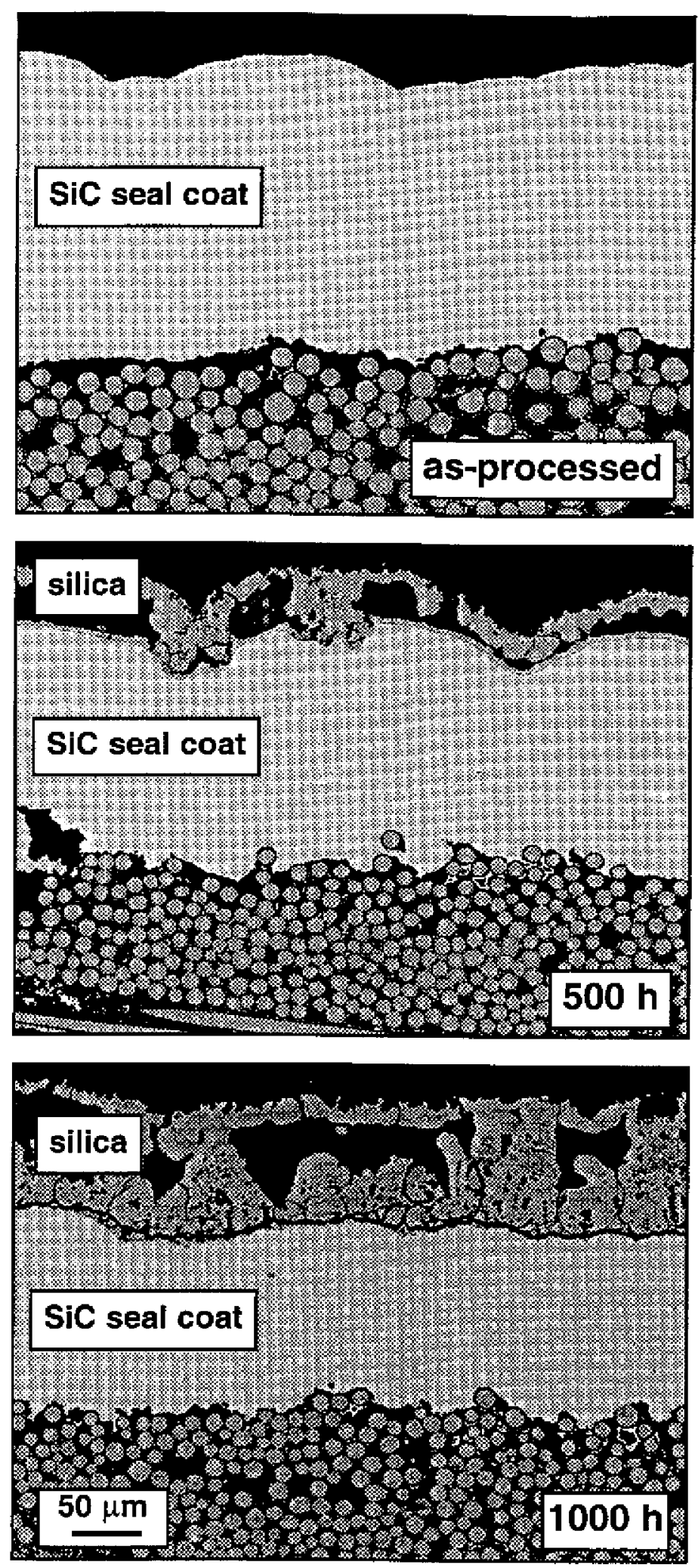

Figure 12. CVD SiC seal coat oxidized for 500 and $1000 \mathrm{~h}$. It was determined from direct microstructural measurements that the SiC seal coat recessed by oxidation at a linear rate of
approximately $45 \mu \mathrm{m} / 500 \mathrm{~h}$.

\section{CONCLUSIONS}

Comparison of results from laboratory and combustor exposures demonstrated that the ORNL rig provides a valid simulation of CFCC microstructural degradation at a rate which is comparable to that observed in actual combustor environments. The rig allows for the necessary high sample throughput to assess damage accumulation and corrosion mechanisms for extended periods of time.

\section{ACKNOWLEDGEMENTS}

Research sponsored by U. S. DOE Office of Energy Efficiency and Renewable Energy, Office of Industrial Technologies for both the CFCC Program under contract DEAC05-96OR22464 with Lockheed Martin Energy Research Corp. and the CSGT Program under contract DE-AC0292CE40960 with Solar Turbines Inc. Our gratitude is extended to D.W. Coffey, M. Howell, and T.S. Geer for technical assistance.

\section{REFERENCES}

Etori, Y. et al., 1997, "Oxidation Behavior of Ceramics for Gas Turbines in Combustion Gas Flow at $1500^{\circ} \mathrm{C}$," ASME Paper 97-GT-355.

Fox, D.S., 1998, "Oxidation Behavior of CVD SiC and $\mathrm{Si}_{3} \mathrm{~N}_{4}$ from $1200^{\circ} \mathrm{C}-1600^{\circ} \mathrm{C}$," J. Amer. Cer. Soc., 81[4] p. 945-50.

Gray, P., Headinger, M. and Miller, A., 1996, "Long Term Tensile Stressed Oxidation and Fatigue Life of Enhanced $\mathrm{SiC} / \mathrm{SiC} \mathrm{CMCs}$," Proceedings of the 20th Annual Conference on Ceramic, Metal and Carbon Composites, Materials and Structures, M. Opeka, ed., p. 865-877.

Keiser, J.R., Howell, M., Williams, J.J., and Rosenberg, R.A., 1996 "Compatability of Selected Ceramics with SteamMethane Reformer Environments," Proceedings of Cortosion/96, NACE International, Houston, TX, Paper 140.

Opila, E.J., 1994, "Oxidation Kinetics of CVD SiC in Wet Oxygen," J. Amer. Cer. Soc., 77[3] p. 730-36.

Opila, E.J. and Hann, R.E., 1997, "Paralinear Oxidation of CVD SiC in Water Vapor," J. Amer. Cer. Soc., 80[1] p. 197-205.

Opila, E.J. and Jacobsen, N.S., 1998, "Volatile Si-O-H Species in Combustion Environments, "Electrochemical Society Proceedings, P.Y. Hou, et al., eds., The Electrochemical Society, Pennington, NJ, Vol. 98-9, p. 524-34. 
Opila, E.J., 1999, "The Variation of the Oxidation Rate of SiC with Water Vapor Pressure," accepted for publication in J. Amer. Cer. Soc.

Price, J.R., Jiminez, O., Faulder, L., Edwards, B., and Parthasarthy, V., 1998, "Ceramic Stationary Gas Turbine Development Program - Fifth Annual Summary," ASME Paper 98-GT-181.

Robinson, R.C. and Smialek, J.L., 1998, " $\mathrm{SiO}_{2}$ Scale Volatility and Recession of CVD SiC in a High Pressure Bumer Rig." Electrochemical Society Proceedings, P.Y. Hou, et al., eds., The Electrochemical Society, Pennington, NJ, Vol. 98-9, p. 406-17.

Simpson, J.F., Parthasarathy, V., and Fahme, A., 1997, "Testing of Monolithic Ceramics and Fiber-Reinforced Ceramic Composites for Gas Turbine Combustors," Ceramic Engineering and Science Proceedings, 18(4) p. 229-238.

Stambler, I., 1997, "ARCO Operating Ceramics Centaur to Evaluate Actual Field Service," Gas Turbine World, Sept.-Oct., p. $20-22$.

van Roode, M., Brentall, W.D., Norton, P.F., and Pytanowski, G.P., 1993, "Ceramic Stationary Gas Turbine Development," ASME Paper 93-GT-309. 